\title{
دور المعاهدات الدولية فى تعديل الداستور
}

\author{
shel \\ د د هديل صالح الجنابى \\ وزارة التعليم العالى والبحث العلمى \\ الجامعت المستنصريتة - كـليت القانون بالعراق \\ د / على متجيد العصكيلى \\ وزارة التعليم العالى والبحث العلمى لـي \\ الجامعت المستنصريتة - كـليت القانون بالعراق
}




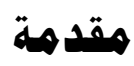

ممـا لاثـك فيسه أنّ السلطة التـي تضع الاستور تسمى السلطة التأسيسية الأصلية، وهي سلطة غير مقيدة ، وغير مشروطة تتلذل في ظروف الفراغ القانوني ؛

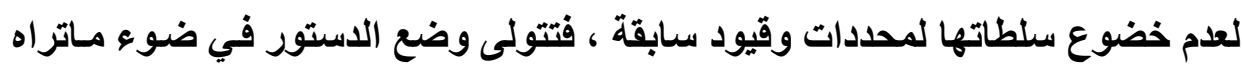

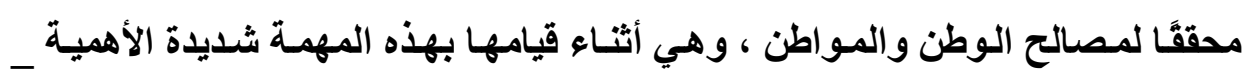
نظرًا لاختلاف عملية وضع الدستور عن القانون العادي _ تقرر بعض القيود الثكلية والموضوعية ، التي يمكن عن طريقها تعديل بعض قواعد الاستور التي تضعه ، فهي

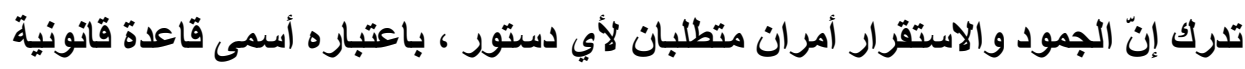

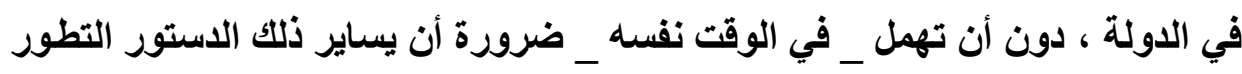
الزمني ومـا يفرزه من متطلبات وحاجيات جديدة لم يستطع المشرعون الاستوريون

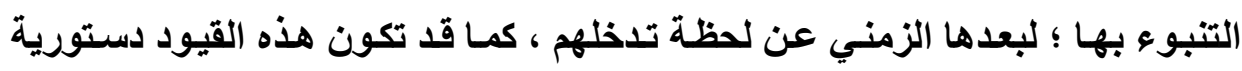
منصوص عليها في الدستور أو قد تكون ذات طبيعة دولية ، وفي أحيان أخرى تتلدخل

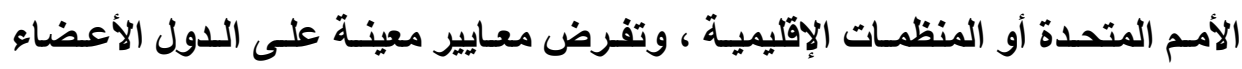

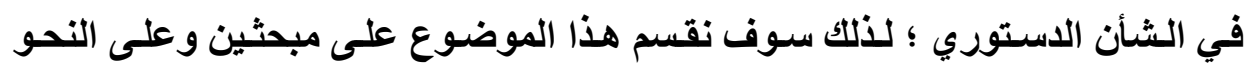
الآتي :• ـ المبحث الأول :- فكرة سلطة التعديل .

• المبحث الثاني :- علاقة المعاهدة الدولية بتعديل الاساتير الوطنية .

مجلتّ البحوث القانونيت والإقتصاديت ابr 


\section{البحث الأول}

\section{فكرة سلطة التعديل}

وجود الاستور يفترض تعديله ، وتعديل الاستور يفترض العودة إلى فكرة أو

نظرية السلطة المؤسسة ، فإقامـة الاستور وتعديله ، همـا مسألتان تطرحان في إطـار فكرة أو مفهوم السلطة المؤسسة ، أن تقيم الاستور ، وتعديل مـاتمّ إقامته ، يجب أن يعود منطقيًا ، إن لم يكن واقعيًا إلى سلطة واحدة هي السلطة المؤسسة . (') ففي الدول ذات الدساتير المرنـة يمكن تعديل الاستور كـالقوانين العاديـة ، غير أنّـهـه إذا كانـت المـواد الدستورية المنـوي تعديلها أسـاسية ، تـدعو الحكومـة في أغلب الأحيان إلى انتخابـات عامـة لتحصل على اللدعم الشعبي واختيـار أكثرية مــن النواب مؤيدة لمشروع التعديل . (ن)

أما في الدول ذات الدساتير المدونة والجامدة فسمو الاستتور يتضمن إجراءات خاصـة : التعـديل الاسـتوري ـ تعديل بعض مـواد الاسـتور يعود للسلطة التأسيسية المشتقة ، أمـا في حسال تعديل الدستور كـاملاً يتمّ الإجراء بمـنح السلطة التشريعية صلاحيات موازية لصلاحيات السلطة التأسيسية الأصلية ، غير أنّ صفة الجمود التي تتصف بها بعض الاساتير لاتعني عدم قابليتها للتعديل ، فضرورات التغيير التي ترافق

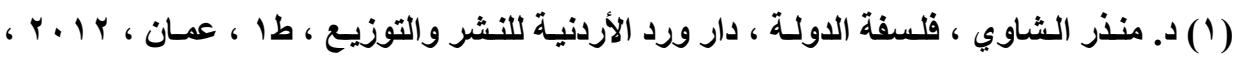
صrar

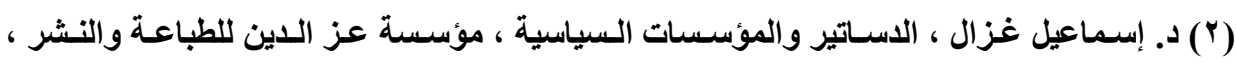

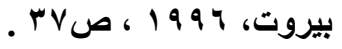


حياة المجتمع تقضي بإجراء التعديلات الدستورية ، لكن درجة المادة على وضع القيود على نشاط التعديل الاستوري . عليه سوف نقسم فكرة سلطة التعديل على ثلاثة مطالب وعلى النحو الآتي : • المطلب الأول :- مفهوم التعديل الاستوري • • المطلب الثاني :- مصادر التعديل الاستوري . • المطلب الثالث :- القيود الاستورية على سلطة التعديل .

\section{المطالب الأول}

\section{هفهوم التعديل الدستوري}

إنّ الاستور ، هو مجموعة قواعد تنظم الدولة في الأساس ممارسـة السلطة في الدولـة ، كمـا قد ذهب بعض الفقهاء إلى أنّ القوانين الدستورية تلـزم السلطات التي أوجلتها هذه القوانين ، ولكنها لا تلزم الأمة على الإطلاق ، فلها أن تعدلها متى أرادت بدون التقييل بأي شكل معين ، على ذلتك فمن حق الأمسة أن تنيب عنها في كل وقت (') ممثلين يمثلوها في القيام بهذا التعديل ـانيل

لهــذا يمكنــــا أن نُعـرّف التعـديل الاســتوري مـن الناحيـة اللغويــة وهـو " تعديل الثيء يعني تقويمه ، يقال عدّله تعديلاً فاعتدل ، أي قوّمه فاستقام ، وكل مثقف

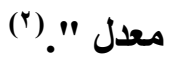

(1) د. كمال الغالي ، مبادئ القانون الدستوري والنظم السياسية ، المطبعة الجديدة ، دمثق ، 19V7، ص

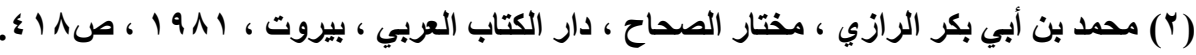


وجاء في (The Oxford Companion to Law ) التعديل " هو تغيير في نص ما ، باستبداله ، أو تغيره أو إضافة إليه ، أو بكل هذه الوسائل مجتمعة الغرض

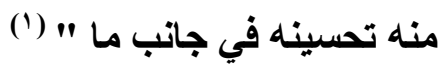
ومن الناحية الاصطلاحية جاء في المعجم الاستوري ، بأنّ التعديل ، هو اقتراح تغيير نص يخضع لتصديق الجميـة النيابية عليه ، وحقّ التعديل هو نتيجة طبيعية للحق العام في المبادرة حسب تعبير ( Engine Pierre) ، وقد استعاره المجلس الاستوري ، ولم يظهر بهذه الصفة في الدساتير الفرنسية الأولى . كما أنّ التعديل بالمغنى الواسع يثمل أي تغير في الاستور سواء انصراف أثره

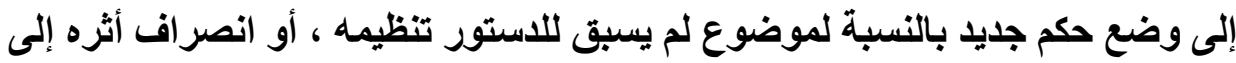
تغير الأحكام الدستورية المنظمة لموضوع ما بالإضافة أو بالحذف . (") بناء عليه فإنّ السلطة التي تعلل الاستور لا يمكن أن تكون بعيدة ، إن لم تكن

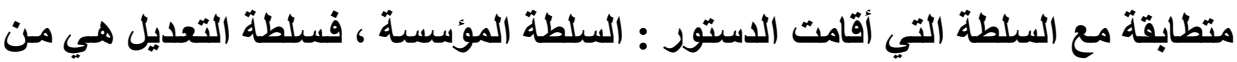

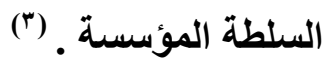

جدير بالذكر أن هناك مجموعة من المصطحات المرادفة للتعديل منها ، التغيير،

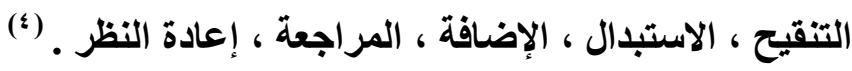

(1) David m . walker claranotion paris, 1980 , p51_52.

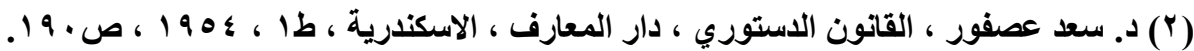

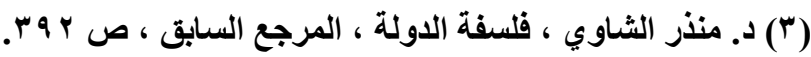

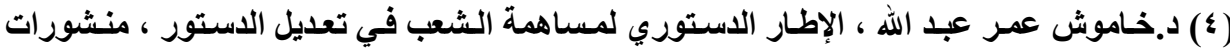

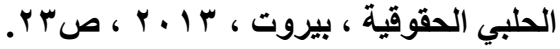


فقد تعددت المفاهيم حول سلطة التعديل ، عليه سوف نقسم هذا المطلب على

$$
\text { فرعين ، وعلى النحة الآتي :- }
$$

• الفرع الأول :- المفهوم التقليدي لسلطة التعديل .

• الفرع الثاني :- المفهوم الواقعي لسلطة التعديل .

\section{الفرع الأول}

\section{المهوم التقليدي لساطة التعديل}

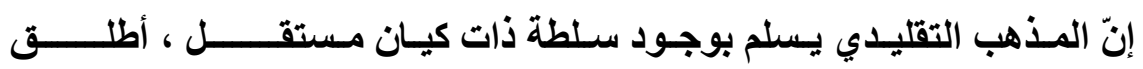
عليهـــا اسم " السلطة المؤسسة " ، ومهمة هذه السلطة هي إقامـة الدستور أو خلق الاستور ، فهي سلطة مؤسسة ؛ لأثّا تؤسس الدولة حيث تقيم الدستور (')، والسلطة المؤسسة حين تقيم الاستور لا تتقيد بأية قاعدة سابقة الوجود على نشاطها هذا ، أي لا تتبع في ذلك أي إجراء فهي حرة في عملها ، تلقائية في خلقها ، لا يؤطرها شيء ولا

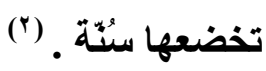
غير أنّ من الحقائق الثابتة والمسلمة في هذا الخصوص ، إنّ النظام الاستوري

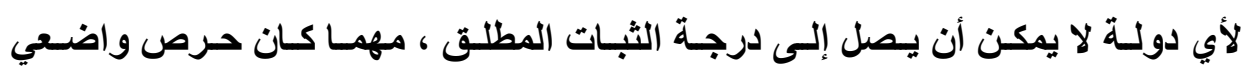
الاساتير على تجميدها ، فالنظام الاستوري لا بدّ وأن يسار قانون التطور المستمر ، ولا بدّ أن يكون هناك تنظيم خاص يجب اتباعه لتعديل القواعد الدستورية ـ معقدًا كسان

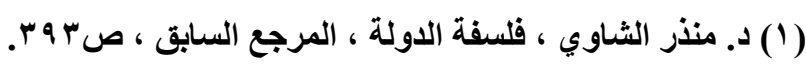

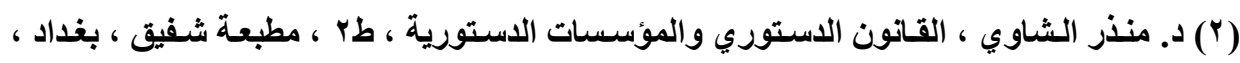

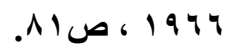

مجلتّ البحوث القانونيت والإقتصاديت 
أو مبسطا ـ حتى لا تؤدي الضرورة والحاجة المستمرة إلى تعديلها بطريق آخر غير قانوني كانقلاب أو ثورة ـ فكما يقول البعض إنّ الاستور الذي لا يسمح بإجراء تعديل

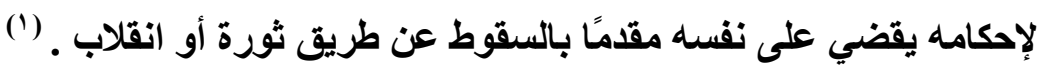

عليه فإنّ السلطة المؤسسة ، هي سلطة نص عليها الاستور ونظم نشاطها ،

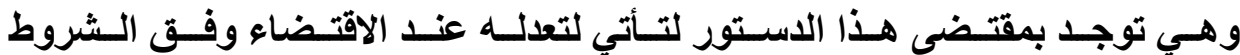

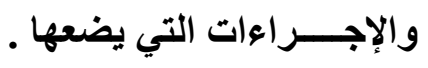

كما أجمع الفقه الدستوري في غالبيته على استحالة الجمود المطلق للاسـاتير

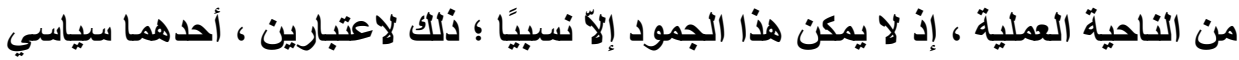
، والآخر قانوني ، والاعتبار السياسي يمثل دستور الدولة وهو بلا شكك واجهة النظام الدستور والسياسي فيها ـ ليس في حقيقته إلاً انعكاسًا للظروف و الأوضاع التي تعيشها

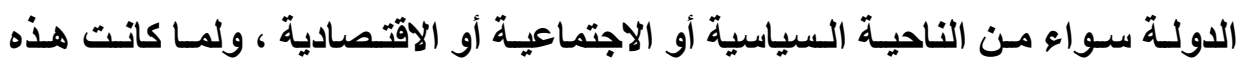

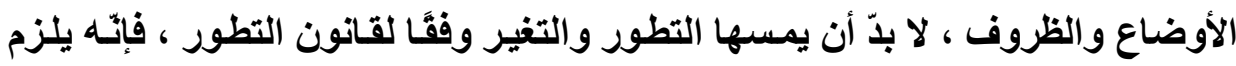
تعديل الدستور ، حتى تساير وتتماثشى مع مايصيب هذه الظروف والأوضساع من تطور مماثل ، وإلا انفصلت النصوص عن الواقع ، الأمر الذي يؤدي إلى ضرورة تعديلها بطريق غير قانوني أي عن طريق الانقلابات أو الثورات .

أمـا الاعتبار القـانوني ، فمناطه تعارض سيادة الأمـة وفكرة الجمود المطلق

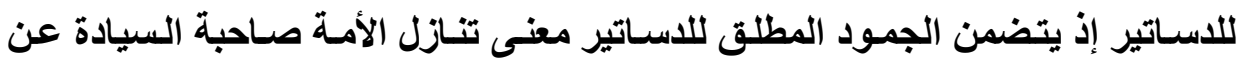

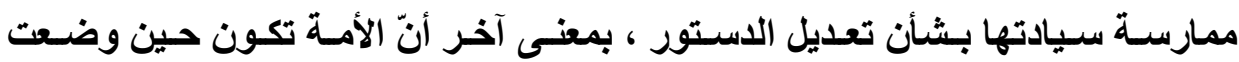


الاستور الجامد جمودًا مطلقًا ، قد حرمت نفسها من ممارسـة حقها في السيادة ، فيمـا يتعلق بثأن تعديل الاستور وفي إلغائه إذا ما رأت مقتضى ذلك ـ (')

\section{الفزرع الثثاني}

\section{الفهوم الواقعي لساطة التعديل}

إنّ معظم الاسـاتير تنص عن طريـق تعديلها على أسـاس أنّ السلطة الأولى لا تخضع للتحديد القانوني ولا تغير بواسطة القانون ؛ لأثّها سلطة تعلو على القانون ، بينمـا تتصف السلطة الثانيـة ، وهـي سـلطة التعديل بأنّهـا محاطة بالقـانون أو سـلطة ذات طبيعة قانونية ، ويأتي علو السلطة التأسيسية الأصلية على القانون ، من صعوبة أو استحالة إيجاد تغير قـانوني للأعمـال التي تقوم بها لتنظيم الدولة لأول مرة ، حيث لا يمكن القول بوجود قواعد قانونية سـابقة على ميلاد الدولة ، وعكس ذلك توصف السلطة التأسيسية المشتقة التي تعدل الدستور بأتهـا مـن طبيعة قانونية وواقعيـة ؛

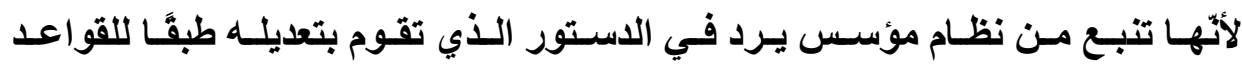

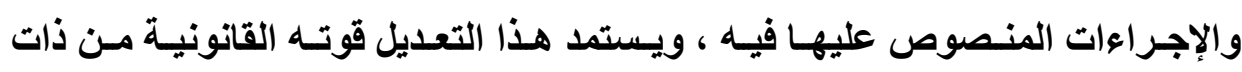
الاسـتور ولـيس مسن ذات السلطة التـي تــلـل على عكس الحكم في حالـة السلطة

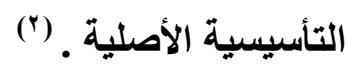

$$
\text { (1) د. إبراهيم عبد العزيز شيحا ، المرجع السابق ، ص • ^. }
$$

(2)O.Duhamel et Y. meny , Dictoonnaier constitionnel , puf ,paris , 1992 , p. 777. 
بناءً عليه فِانّ سلطة التعديل لا تحمل قيمتها في ذاتها فهي لا قيمة لها إلاً بقدر ما تعبر عن إرادة الحكام المطلقة ، وهذا مايعبر عنه الأستاذ جورج بردو حين يقول إنّ " إجراء التعديل لا يمكن أن يعتبر إلاً كشكل مقترح للسلطة المؤسسة ، كتكنيك مناسب ، لكن ليس كاطار ضروري ". (1)

\section{الاطلب الثاني}

\section{همادر تعديل الدستور}

كمـا هو معلوم إنّ السلطة التأسيسية الأصلية هي التي تقوم بوضع الدستور للاولة ، إلاً أنّ السلطة التأسيسية الت يتختص بتعديل الدستور حسب الإجراعات ووفق الثروط المحددة التي ينص عليها هذا الدستور تعدّ تأسيسية مشتقة ( سلطة التعديل ) . كما أنّ سلطة التعديل ، هي السلطة المختصة بتعديل الدستور ، إلآ هذا لا يعني تعديل الاسـتور حكر على سـلطة التعديل ، بـل يمكن أن تقوم بهـذه المهمـة السلطة الأصلية أو السلطة السياسية ولا بـدّ أن نفرّق بين طبيعة كل من السلطة التأسيسية الأصلية باعتبارهـا تأسيسية للاستور وطبيعة ووظيفـة السلطة التأسيسية المشتقة

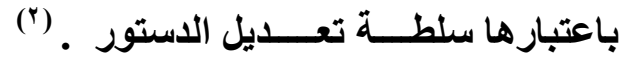
عليه سوف نقسم هذا المطلب على فرعين ، وعلى النحو الآتي :• الفرع الأول :- السلطة التأسيسية الأصلية .

• الفرع الثاني :- السلطة التأسيسية المشتقة ( سلطة التعديل ) .

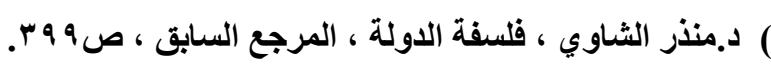

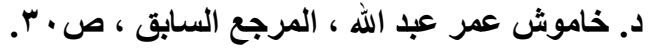




\section{الفرع الأول \\ السلطة التأسيسية الأصلية}

تعطي هذه السلطة لدولة ناشئة دستورًا جديدًا ، وتحدد قواعد عمل المؤسسات

(') (العامة . (1)

كما أثّها تباشر بإعداد دستور جديد بعد انهيار المؤسسات الاستورية القائمـة نتيجة انقلاب أو ثورة أهلية ـ هذه السلطة تخلق الدولة وتجسد الفكرة القانونية الواجب تحقيقها في المجتمـع ـ لكن هنـاك تميز بـين السلطة المؤسسة الأصلية ، والسلطة المشتقة أي السلطة التي تعدل الاستور •

هذا وإنّ سلطة التعديل تختلف عن السلطة التأسيسية ؛ لأنّ التعديل يتعلق بنص أو بمجموعة النصوص الاستورية الموجودة بالدستور ، في حين أنّ السلطة المؤسسة هي السلطة التي تقوم بوضع الاستور وليس بتعديله كمـا أسلفنا ـ لهذا كانت علاقة السلطة التأسيسية بمسألكة التعديل اسـتثنائية متعلقة ببعض المسائل الجوهريـة في الاستور ، والتي يعود فيها الفصل الأمة مباشرة ؛ لأثّها لا تتعلق بأحكام السلطة ولكن بمبادئ الدولة والأمة ، كتغير النظام ذاته من ملكي إلى جمهوري أو العكس ، أو بشكل

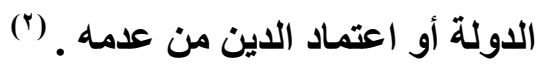

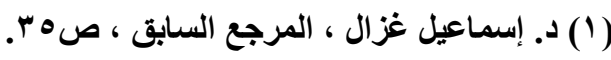

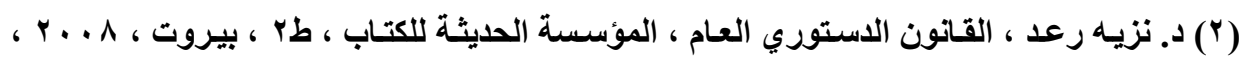


هكذا نجدّ أنّ بعض الدول تنتخب جمعية تأسيسية تنحصر مهمتها فقط في إجراء عمليـة التعديل الاسـتوري وأخــت بهذه الطريقـة الولايـات المتحـدة الأمريكيـة ، هذه الطريقة في دساتيرها ، عند القيام بالتعديل ، كذلك اعتمدتها فرنسا في دستور ^ ؟ ^1 ـ ـ ممسا سـبق يتضح لنـاوجـود علاقـة معينـة بين السلطة التأسيسية الأصلية ، والسلطة التأسيسية المشتقة ( سلطة تعديل الاستور ) قوامها وجود نوع من التدرج بين هاتين السلطتين ، تعلو بمقتضاه الأولى على الثانية ـ (')

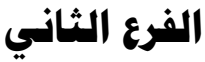

\section{الساطة التأسيسية المشتقة ( سلطة التعديل )}

تنص الاســتير على السلطة المشتقة ، وهذه السلطة تكون مخولـة بتعديل نصوص الاسـتور ، وفق الإجراءات والضضوابطو الشروط المحددة في صلب نفس

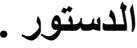

Pouvoir Constituant ） بعبارة أخرى فالسلطة التأسيسية المستثقة derive ذات الدستور ، وعن طريق الهيئات التي منحت الحق في إجراء التعديل ، كما أنّ التميز السابق سالف الأكر يؤكد حقيقة أخرى ، وهي اختصاص السلطة التأسيسية الأصلية هو اختصاص غير مشروط() على عكس الأمر بالنسبة للسلطة التأسيسية المشتقة ، التي تخضع للقيود الثكلية والموضوعية التي فرضتها السلطة الأولى ؛ لإمكان إجراء

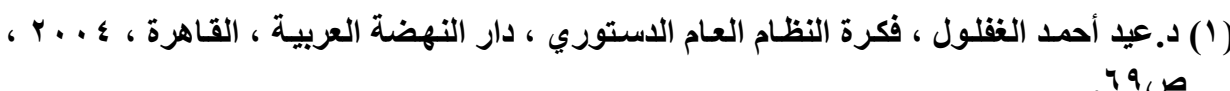

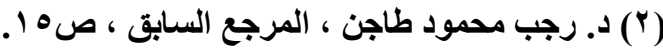


التعديل الاستوري ، الهدف منها إلى منع هذه الأخيرة من ممارسة عملها في تعديل أي نص من نصوص الدستور في خلال فترة زمنية محددة أو في ظل ظروف معينة . (')

\section{المطالب الثالث}

\section{القيود الدستورية على سلطة التعديل}

مما لا شك فيه أنّ هناك كثير من الاساتير تتص على بعض الموضوعات التي لا يجوز المساس بها ، كما تنص على أنّ بعض المواد لا يجوز المساس بها خلال فترة زمنية معينة ، ومن ثم تتمتع تلك المواد بالحصانة الدستورية تجاه تعديلها ـ (ن) كما أنّ هذه القيود تأخذ في الأغلب شكلين ، من جهة يعلن الاستور في إحدى نصوصه بـأنّ واحد أو أكثر من مواده لا يمكن أن تكون أبدًا موضوع تعديل ـ فهنـاك دساتير ، لكي تضمن استمرار النظام الذي تقيمه ، تعلن بـأنّ بعض المواد ، التي تحدد الأسس الجوهريـة للنظام السياسي والتي تعبر عن " المثل السياسي " لمؤسسيه لا يمكن أن تكون موضوع تعديل دستوري ، بعبارة أخرى ، يمكن أن ينص الدستور على

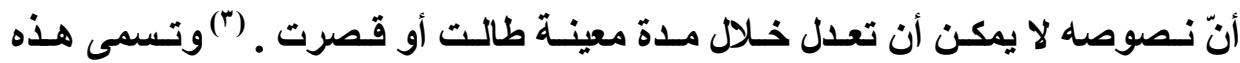
النصوص بـ" القواعد فوق الدستورية " ويقصد بها سمو بعض القواعد الموصوفة ب" الركائز " على نصوص الدستور وعلى القواعد المعلنة صراحة في بعض نصوص 
القانون الموجودة بصورة ضمنية ، أو مضمونها ملزم لواضـح الاستور ومن ثم فِانّ

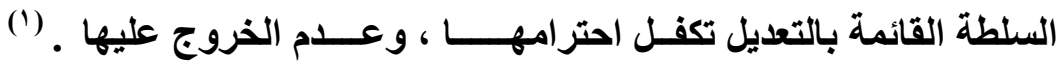
عليه سوف نقسم هذا المطلب على فرعين ، وعلى النحو الآتي :• الفرع الأول :- القيود الزمنية لتعديل الدستور . • الفرع الثاني :- القيود الموضوعية لتعديل الدستور ـ

\section{الفرع الأول}

\section{القيهود الزهنية لتعديل الدستور}

هذا النوع من الحظر الذي أصبح نادرًا لا غبار على صحته ، فإجراء التعديل لا يتمّ قبل مرور فترة زمنية معينة حددها الدستور القـائم ، الغايـة من هذا الحظر عدم اللجوء المستمر إلى تغيير الدسـاتير قبل رسوغها ، وإعطاء المشرع فترة من الوقت للتأمسل والتـروي قبل الإقدام على تعديل الاسـتور ـ نـص على هـا الحظر الاسـتور الفرنسي لعام Vq I الذي حرم اقتراح التعديل قبل مرور أربع سنوات وكذلك الدستور الفرنسي لعام 1901 في المادة 9 19 على عدم إجراء التعديل في الظروف الاستثنائية العصيبة التي تمرّ بها البلاد ، مثل ظروف إعلان حالـة الطوارئ أو الأحكام العرفية

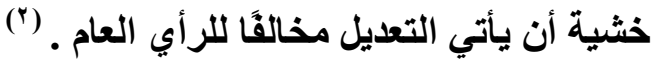

(1) د.محمد فوزي نويجي ، مسؤولية رئيس الدولة في الفقه الإسلامي ، دار الجامعة الجديدة للنشر ، ملائل

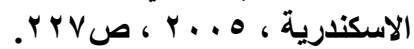
(ץ) د.إسماعيل غزال ، المرجع السابق ، صه هـ. 
كمـا حظر التعديل الدستوري في حالة خلو منصب رئيس الجمهوريـة ، وهذا الحظر لا يأتي من المـادة 9 ^من دستور 1901 الفرنسي التي تحدد إجراعات تعديل الاستور وإنّما تأتي في الفقرة الأخيرة من المادة السـابعة من ذات الاستور التي تحدد طريقة انتخاب رئيس الجمهورية وشروط وضوابط لك .

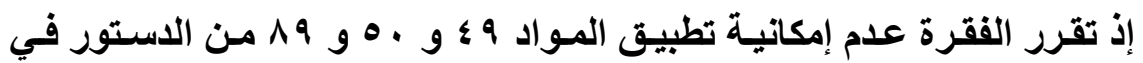
حالة خلو منصب رئيس الجمهوريـة ، وكذا الأمر خلال القترة البينية التي تبـأ من الإعلان النهائي عن عجز الرئيس عن مباشرة مهامه الرئاسية وتتتهي باختيـار رئيس آخر حلقَا له . (1)

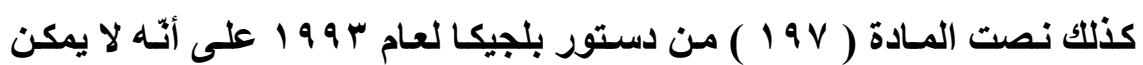
تعديل الدستور خلال فترة الوصاية على العرش حيث نصت تلكك المـادة على أنّه خلال فترة الوصاية على العرش لا يمكن وضع أي تعديل على الاستور فيما يتعلق بالسلطات (الاستورية للملك . (ن)

أما الاستور الإسباني في نص المادة ( 99 (19 ) من دستور 19 منصت على عدم جواز الثروع في تعديل الدستور في أوقات الحرب أو في حالة توافر ظرف من الظروف المنصوص عليها في الاستور ، هي حالة الاستفتاء العام ، وحالة الحصار

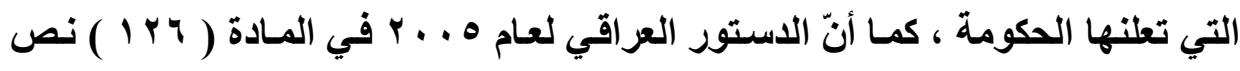
على عـدم جـواز تعـديل المبـادئ الأسـاسـية في البـاب الأول المتعلــة بــكل النظــام

(1) M-F. Rigaux , Latheorie des limites materielles a lexeice de la function constituante, paris , Bruxelles , 1985 , p.50

$$
\text { (ץ) د د. رجب محمود طاجن ، المرجع السابق ، ص ه ه. }
$$


السياسي، والحقوق والحريـات الواردة في الباب الثاني من الدستور إلآ بعد دورتين انتخابيتين متعاقبتين ، أي بعد مرور ثماني سنوات على تنفيذ الاستور .

\section{الفزرع الثاني}

\section{القيرود الموضووية لتعديل الدستور}

تشمل هذه القيود أمورًا محددة يستقصي على سلطة التعديل المساس بها وغالبًا مـا تختلف هذه الموضوعات من دولـة لأخرى حسب مفهومها ؛ لتبني نظام سياسي

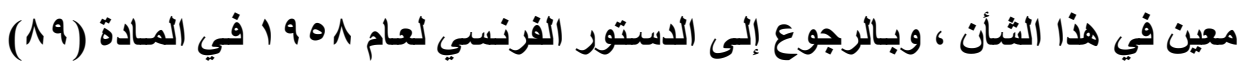
يمكن رصد قيد موضوعي واحد ، تلتزم السلطة التأسيسية المشتقة ( سلطة التعديل ) باحترامه عند إحداث أي تعديل دستوري جديد ، وهذا القيد تكرسـه الفقرة الأخيرة من المادة ( 9 ( ) التي تنص على أنّ " الثكل الجمهوري للحكومة لا يمكن أن يكون محلاً (') لتعديل دستوري

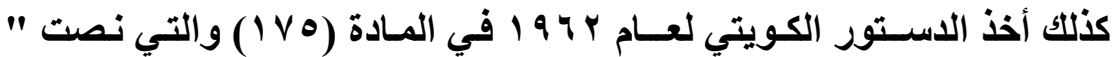
الأحكام الخاصة بالنظام الأميري للكويت ، وبمبادئ الحرية والمساواة المنصوص عليها في هذا الدستور لا يجوز لقتراح تنقيحها ، مـالم يكن التنقيح خاصنًا بلقب الإمـارة أو بالمزيد من ضمانات الحرية والمساواة ". (؟) 
هذا وأخذ دستور موريتانيا لعام 1971 في المادة ( 99 ) و والتي نصت على (لا

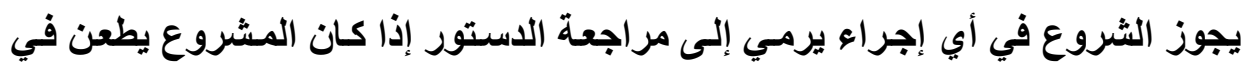

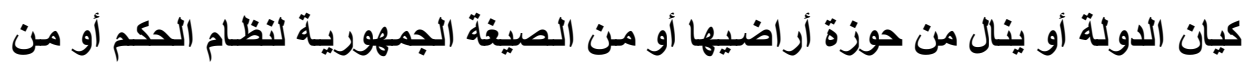
الطابع التعددي للايموقراطية الموريتانية ) .

كنلك الاستور البرازيلي لعام ؛ ب9 1 والذي نصّ على ( عدم إجراء أي تعديل

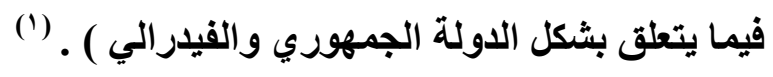

كذلك الاستور الإيطالي لعام V؟ 19 والذي نص على أنّه (لا يجوز أن يكون

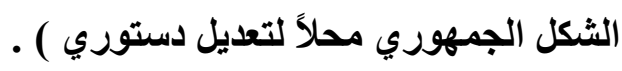

هذا وترجع الرغبة في النص على حظر تعديل بعض أحكام الاسساتير إلى حماية

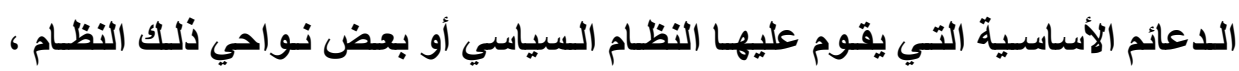
و الرغبة في ضمان بقاء هذه الدعائم دون تعديل أو تبديل .

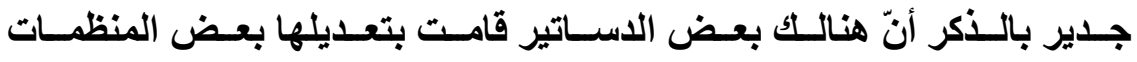
والمعاهدات الدولية ، هذا ماسوف نبحثه في المبحث الثاني وهو دور المعاهدات في بوني

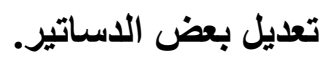




\section{المبحث الثاني}

\section{علاقة المعاهـدة الدولية بتعديل الدساتير الوطنية}

المعاهدة الدولية ، هي اتفـق دولي يعقد كتابة بين أثـخاص القانون الدولي

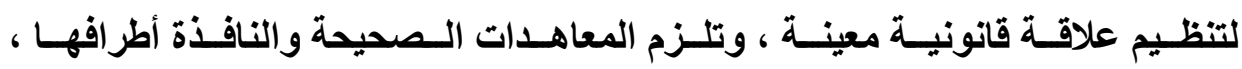

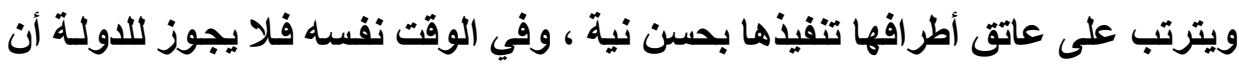

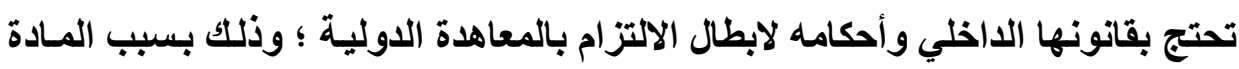

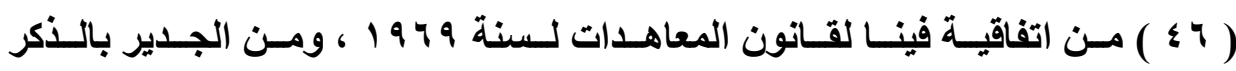

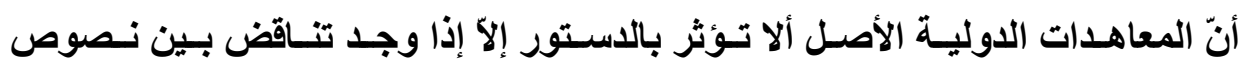
المعاهدة ونصوص الاستور ، الأمر الذي يستدعي دراسة هذا التأثير من خلال ثثلاثئة

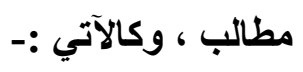

• المطلب الأول :- موقع المعاهدة الدولية ضمن التشريع الوطني .

• المطلب الثـاني :- القيـود التــي تفرضـها المعاهــــــات الدوليـة على تعـديل الاستور.

• المطلب الثالث :- دور المنظمات الدولية في تعديل الدستور . 


\section{المطلب الأول}

\section{هوقع المعـاهـدة الدولية ضمن التشريع الوطني}

إنّ مبدأ تدرج التشريعات من المبادئ التي لها أهمية كبيرة لأجل معرفة ترتيب

ودرجة المعاهدات الدولية فيمـا بينها ، وكذلك بهدف معرفة موقعها ضمن التشريعات الوطنيـة ، وإنّ فهمهـ من أهم الوسـائل التي تؤدي إلى دفع التعـارض بين التشريعات الوطنية والنصوص الدولية ، الأمر الذي يتطلب دراسته دراسة وافية من خلال محاولة لفهـم المبـأ ، وذلـك بعـ التعرف على ماهيـة المعاهـدة الاوليـة ، وذلـك في فرعين وكالآتي :-

$$
\text { • الفرع الأول :- ماهية المعاهدة الدولية وتدرجها . }
$$

• الفرع الثاني :- التشريعات الوطنية وموقع المعاهدة منها .

\section{الفرع الأول}

\section{هاهية المعاهدة الدولية وتدرجها}

المعاهدة الدوليـة هـي اتفـاق يعقد كتابـة بـين أشـخاص القـانون الـدولي العسام لأحداث آثار قانونية معينة وفقًا لقواعد القانون الدولي سواءً تمّ هذا الاتفاق في وثيقة واحدة أو عدة وثـائق ، وذلك بحسب المـادة ( Y ) من اتفاقيـة فينـا لقانون المعاهدات

كما أنّ المعاهدة الدولية قد تأخذ عدة مسميات فقد يطلق عليها تسمية معاهدة أو اتفاقية أو ميثاث أو عهد أو تسمى نظام أو مذكرة تفاهم ، إلآ إنّه طالما كان الاتفاق بين 
شخصين دوليين أو أكثر ومكتوب فهو معاهدة دولية أيبا كانت التسمية لهاب('وكمـا أنّ

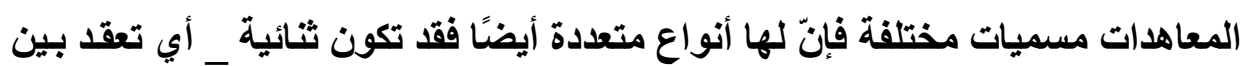
دولتين فقط _ أو جماعية _ عدد أطرافها أكثر من اثثين _ كمـا أنّها قد تكون شـارعة ، أي تلك التي تهدف إلى سن قواعد قانونية دولية جديدة اتنظيم علاقة أشخاص القـانون

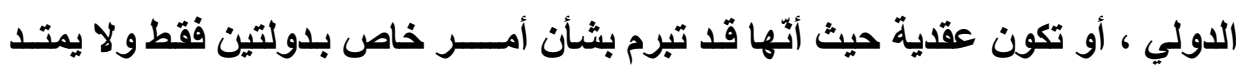

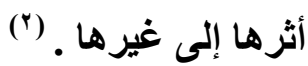
ولكن مع هذا التنوع بأثكال ومسميات المعاهدات الدولية هنـاتك سؤال لابـ من طرحهه هنا ، هل جميع المعاهدات الدولية بمرتبة واحدة أم أنها متباينـة ، ومـاهو الحل في حال تعارض بنود المعاهدات الدولية فيما بينها ؟

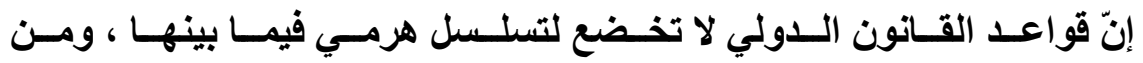
غير المناسب القياس على الطابع التسلسلي للقانون الوطني حيث أن هناك فوارق ثانية

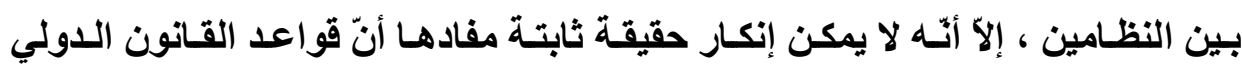
لا تكون بلرجـة واحدة مـن الأهمية وهو الأمـر الذي أكدته المـادة ( به ) من التفاقية

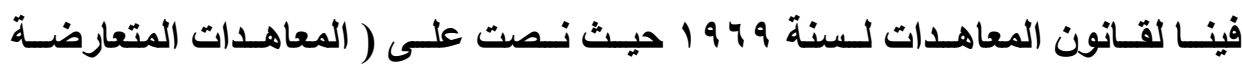

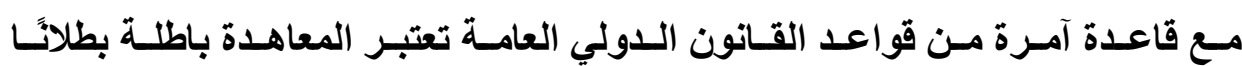

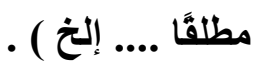

( (1) د. علي صادق أبو هيف ، القانون الدولي العام ، منشأة المعارف بالاسكندرية ، بدون سنة طبع ،

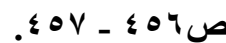

(2) GAMBLE, Reservation to Maltilateral Treaties, Amacroscopic view of state practice, 74 Ajil , 1980 ,p.372 .

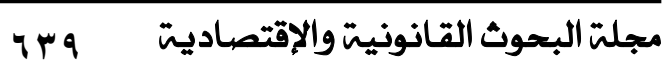


ومن الأمثلة على القواعد الآمرة قاعدة حظر العدوان ، وحظر تجـارة الرقيق

والإبـادة الجماعيـة ، والتمييز العنصري ، والتعذيب ، فضلاً عن القواعد الآمرة فـإنّ هناك قواعد دولية تكون لها أولويـة على سـائر القواعد الأخرى ، كمـا هو الحسال في نصوص ميثاق الأمم المتحدة حيث نصت المادة ( ب ـ 1 ) من ميثاث الأمم المتحدة على ( إذا تعارضت الالتزامات التي يرتبط بها أعضاء الأمم المتحدة وفقًا لأحكام هذا الميثاق ه مع أي التزام دولي آخر يرتبطون به فالعبرة بالتزاماتهم المترتبة على هذا الميثاق ). (') ويتضح مما تقام ما لقواعد الميثاق من أهمية كبيرة ، كما لا يمكنتا إغفال القيمة القانونية للقواعد الدولية ذات الحجية المطلقة فهذه القواعد تعني جميع الدول ويكون لكل المجتمع الاولي مصلحة قانونية في صون الالتزامات والحقوق التي ترتبها ويمكن لأي دولة إثارة المسؤولية الدولية تجاه الدولة التي تنتهك هذه القواعد . وينـاءً على مـا تقدم فـإنّ القاعدة الدوليـة قد تتعـارض مـع قاعدة دولية أخرى وبالتالي تظلب القاعدة الآمرة على سواها من قواعد القانون الدولي ، وكذلك الأمر في

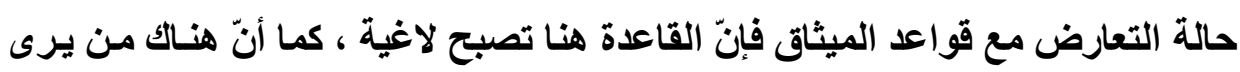
أنّ المعاهدات والاتفاقيات المتعلقة بحقوق الإنسان تكون لها السيادة على غيرها من التشريعات حتى لو كان تشريعًا دستوريًا ، فإنّ القواعد الدستورية التي تنكر حقوق

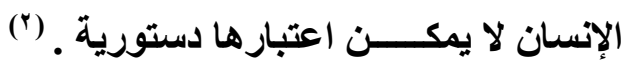

(1) See R AFalk ,on The Quasi _ Legislative Competence of The General dssembly , 66 ATL, 1966 , p. 780 .

(ץ) د. عوض عبد الجليل الترساوي ، المعاهدات الاولية أمام القضاء الدستوري ( دراسة مقارنة أمام

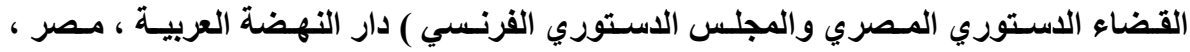




\section{الفرع الثاني}

\section{التشريعات الوطنية وهوقع المعاهدة منها}

بعد أنّ بينـا موقـع المعاهدة عنـــنتازعها مـع قواعد القـانون الدولي وحددنـا القواعد الدولية التي لا يجوز الاتفاق على خلافها والتي تظهر من خلال المعاهدات الدولية فلا بد من الإجابة على سؤال مهم آخر ألا وهو موقع المعاهدات الدولية ضمن

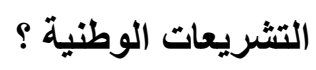

والإجابة على هذا السؤال ليست موحدة بل هناك إجابات متعددة ؛ وذلك بحسب

النظام الاستوري لكل دولة ، إذ هنـايك دول تجعل المعاهدة الدولية أعلى من دستورها

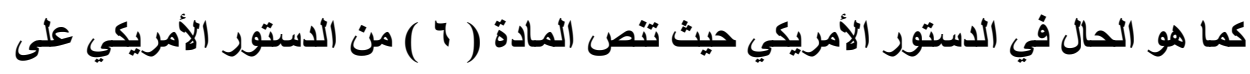

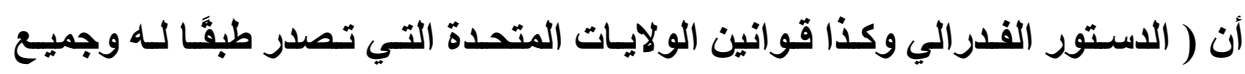
المعاهدات الدولية المبرمة بواسطة الولايـات المتحدة هي القانون الأعلى للبلاد وهي ملزمة لجميع القضاة في جميع الولايات بغض النظر عن النصوص المخالفة المدرجة

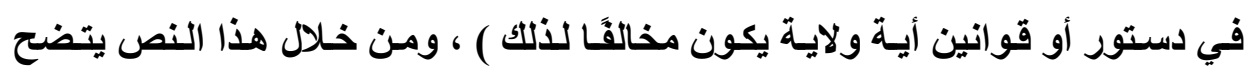
السمو الذي تتمتع بـه المعاهدات حيث تسمو على قوانين ودسـاتير الولايـات المتحدة

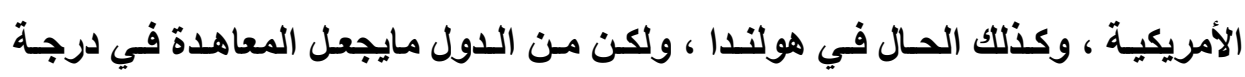

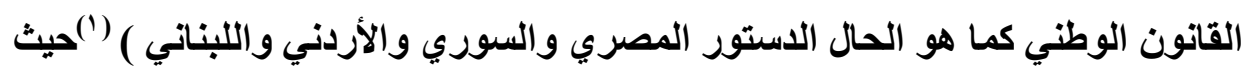

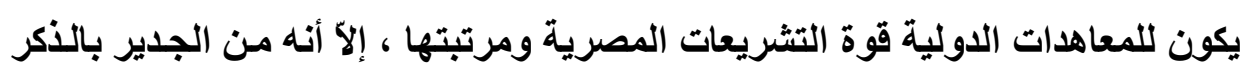
أنّ القضاء الاسـتوري المصري قد بـين في عدة أحكام بـأنّ للمعاهدة الدوليـة مكانـة 
ومرتبة القانون إلاًا أنها تتمتع بافضلية وأعلوية في حال تعارضها ميع القـانون العادي

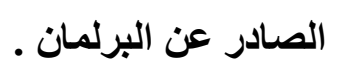

و هناكك من الدول مـا تتعدد فيها درجة المعاهدات الدولية ولا تكون للمعاهدات فيها درجة واحدة ، فالمعاهدات التي يصادق عليها مجلس النواب تكون بمثابة قوانين وطنية ، أما المعاهدات الدولية التي لا تحتاج إلى مصادقة مجلس النواب فتكون بمثابة لا لحة أو لوائح ، وهي الاتفاقيات التي يصادق عليها رئيس الجمهورية بعد موافقة

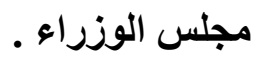

\section{الامطاب الثاني}

\section{القيود التي تفرضها المعاهدات الدولية على تعديل الدستور}

أصبح مـن الثابت إنّ المعاهدة الاوليـة المبرمـة بشكل صـيح وتـام ملزمــة

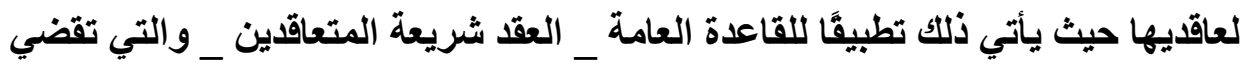

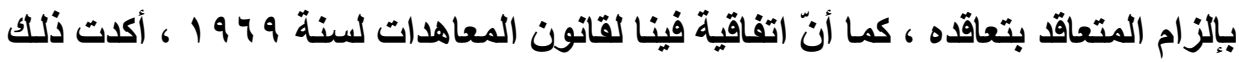

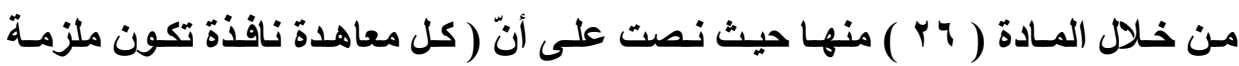
لأطر افها وعليهم تتفيذها بحسن نية ) ، كما لا يجوز لائة دولة أن تحتج بأحكام قانونها

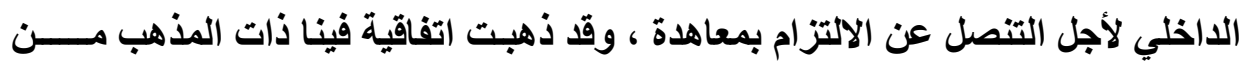

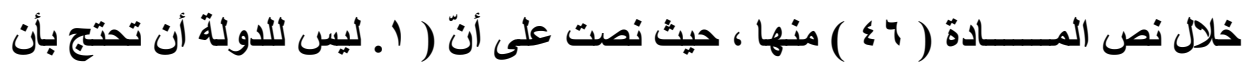

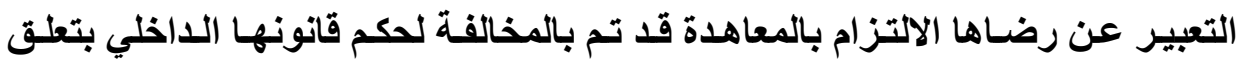

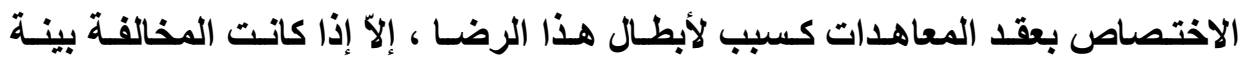
وتعلقت بقاعدة أساسية من قواعد القانون الاخلي ) . ولكن هل التصديق على المعاهدة يجعل من المعاهدة بمثابة قانون ملزم ونافذ داخل الدولة أم أنّ المعاهدة بحاجة إلى إجراء تثريعي آخر ؟والدول المنقسمة إلى عدة 
اتجاهات في هذا المجال ففي الوقت الذي تجد فيه أن كلاً من الولايات المتحدة الأمريكية

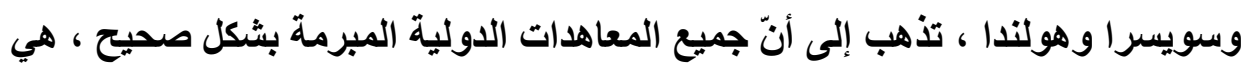

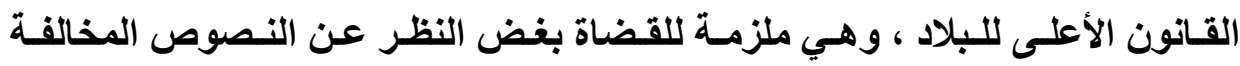
المدرجة ضمن الاستور أو المتضمنة في القوانين العادية ، الأمر الذي يترتب عليه التئه تقييد سلطة تعديل الدستور ، حيث أنّ المعاهدة أصبحت قيد صريح على سلطة تعديل

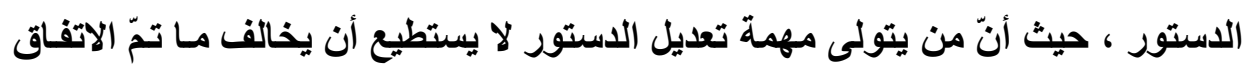

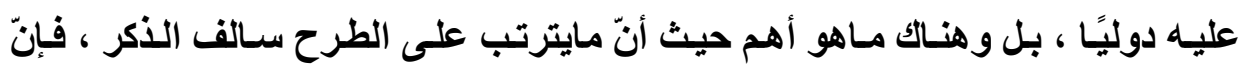

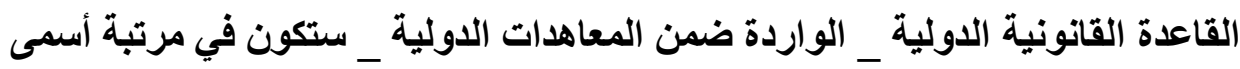

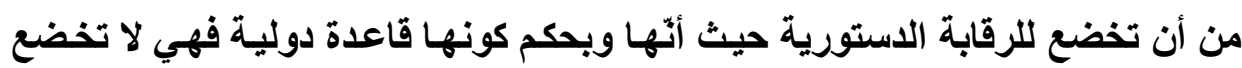

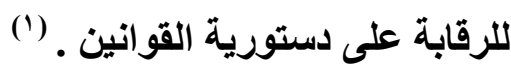
و هذا القيد يمكن ملاحظته في الدول التي تتبنى مذهب وحدة القانون ، ففي هذه

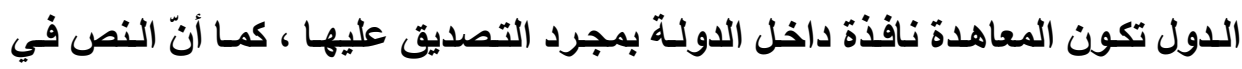

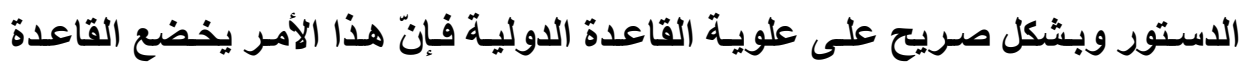

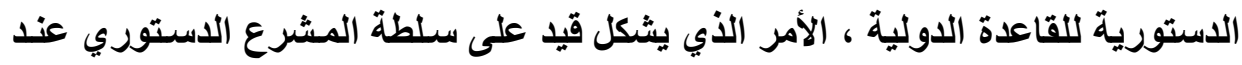

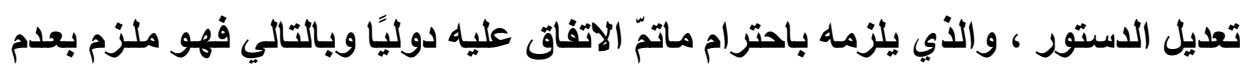

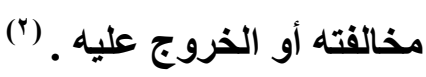
أمسا في الـاول التي تأخذذ المعاهـدة فيها مرتبـة وسطى بين القـانون العسادي

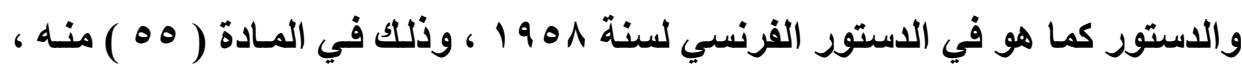

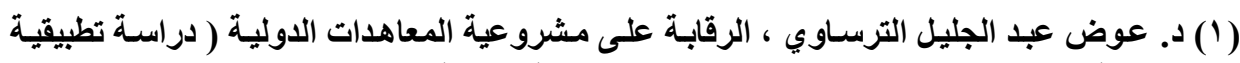

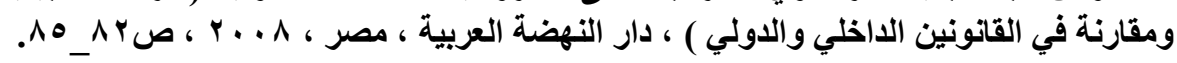

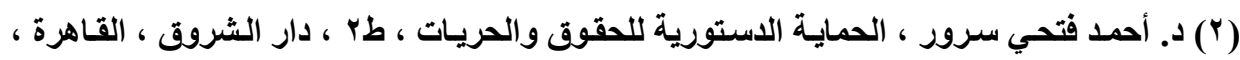
. $v \leqslant$ : r... 
حيث جعل هذا الدستور المعاهدة في مرتبة أعلى من القانون العادي ومرتبة أدنى من

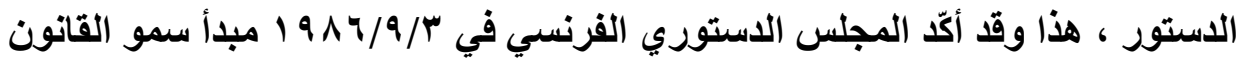

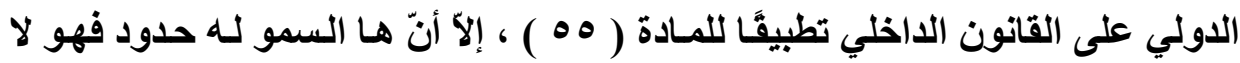
يصل إلى مرتبة القانون الاستوري اللاخلي ، ويترتب على هذا الأمر أنّ الالتزامـات

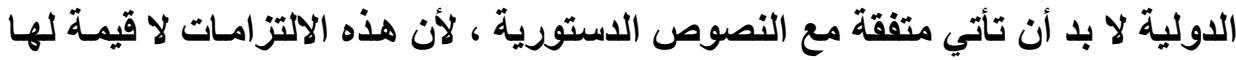

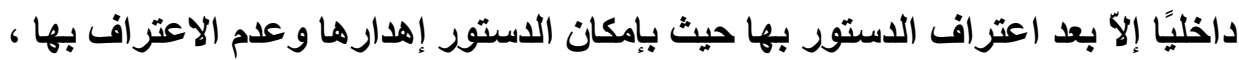

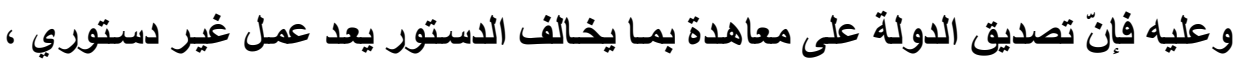
الأمر الذي يتطلب إجراء تعديل للاستور كي يتلائم مع الالتزام الدولي . (') فالقاعدة القانونيـة الدوليـة تبقى نافذة ، ولا يمكن الاحتجـاج بقواعد القـانون

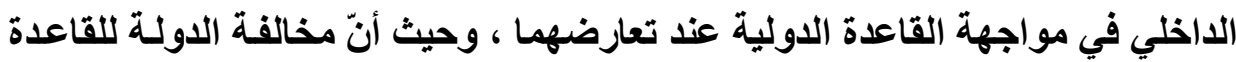
القانونية الدولية يثير المسؤولية الدولية ، كما أنّ الدول في الوقت الراهن الهن ولأسباب كثيرة منها العولمة ، والتقارب الثديد بين الدول ، تسعى إلى جعل القاعدة الدستورية

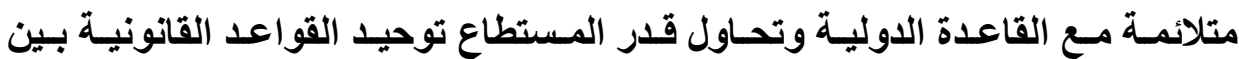

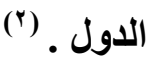

يتضح لنا من كل ماتقام أنّ الدولة لها إرادة حرة في إبرام المعاهدات الدولية ،

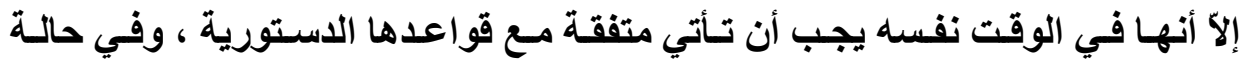
تعارض المعاهدة مع النص الاستوري سيؤدي ذلك إلى تعديل الدستور لأجل القضاء

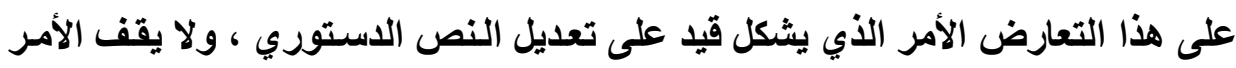
(1) د. عوض عبد الجليل عوض الترساوي ، المعاهدات اللولية أمسام القضاء اللستوري ، المرجع

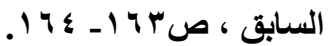
(广) د. عوض عبد الجليل عوض الترساوي ، المعاهدات الدولية أمام القضاء الدستوري ، المرجع

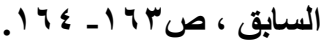


عند هذا الحد بل أصبحت المنظمات الدولية هي الأخرى تتحكم بشكل أو بـآخر وبتعديل الاساتير ، وهو ماسنتاقشه في المطلب اللاحق .

\section{المبلب الثالث}

\section{دور المنظمات الدولية في تعديل الدستور}

تعدّ المنظمـات الدوليـة سـواء ذات الصبغة العالميـة أو الإقليميـة مـن الوسـائل

المهمة في تسوية المنازعات في المجتمع الدولي ، حيث أنّ مواثثقها _ وهي معاهدات دولية منشئة لمنظمة دولية _ في الغالب تميز بين ماهو داخل في صميم الثأن الداخلي للاول ، وما يخرج عن هذا الوصف بهدف معرفة القضايا التي يمكن أن تتدخل لإيجاد

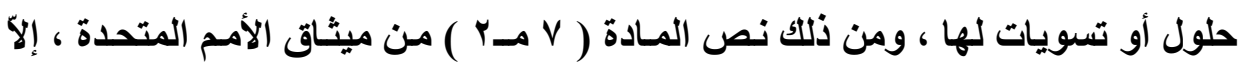
تحديد مـاهو داخل ضمن الاختصاص الداخلي ومـايخرج عنـه ليس نهائبًا ولا قطعي ، فلكل دولـة الحق في اختيـار نظامها السياسي ، والاقتصادي ، والاجتمـاعي مـن دون تلخل(') إلأ أنه حتى هذه الأمور يمكن مناقشتها داخل أجزة الامم المتحدة على اعتبار

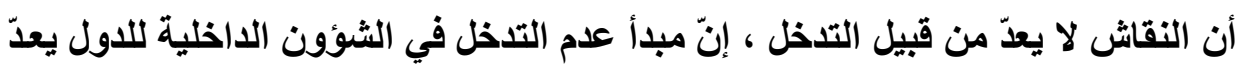
بمثابة تطبيق عملي لفكرة سيادة الدول ، وهو أثر من آثارها ؛ لذلك يجب عدم المساس

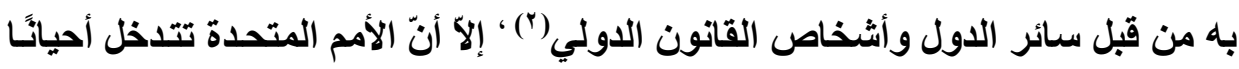
في مسائل تعد من الشأن الداخلي لأهداف مختلفة كما هو الحال في تلخلها بهدف تقديم المساعدة القنية من أجل وضع النصوص القانونية كما هو الحال في ناميبيا حيث وضع

( ) د.أحمد أبو الوفـا ، الوسيط في قانون المنظمـات الدولية ، طه ، دار النهضة العربية ، مصر ، ( ب... (ץ) د. إبراهيم أحمد شلبي ، التنظيم الدولي ( دراسـة في النظريـة العامـة والمنظمـات الدولية ) الدار

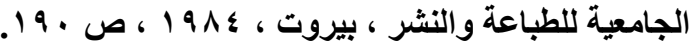




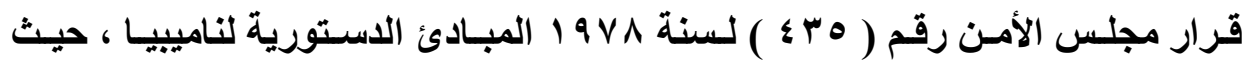

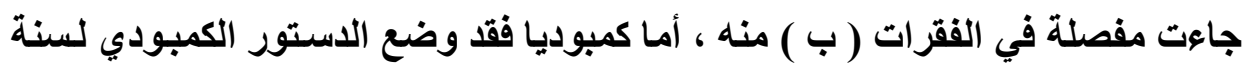

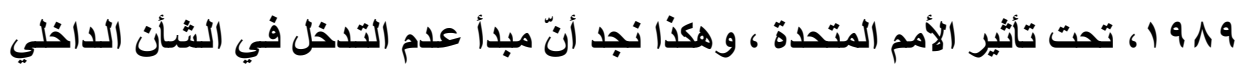

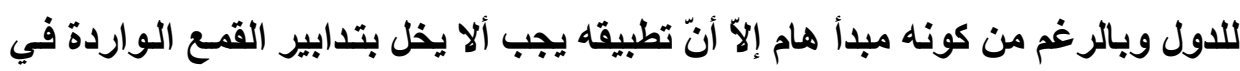
الفصل السابع من ميثاق الأمم المتحدة (1)؛ لذلك بإمكان المنظمة التدخل للحفاظ على لإنى الأمن والسلم الدوليين وبأي شكل من أشكال التدخل .

كما أنّ المنظمات أقليمية هي الأخرى قد تتلذخل بشكل أو بـآخر لأحداث تعديلات

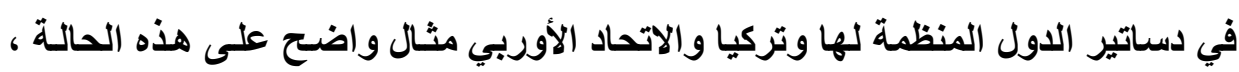

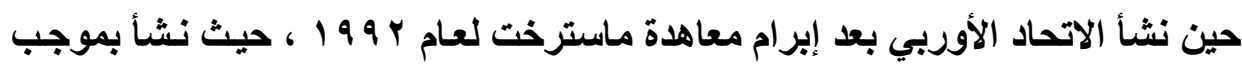

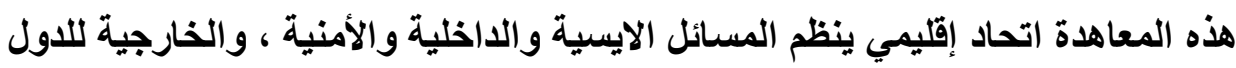

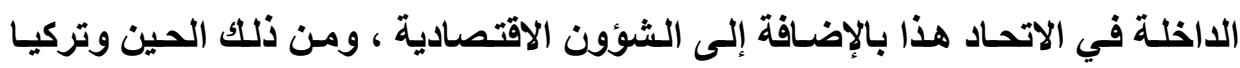
تحاول الاخول ضمن عضوية هذا الاتحاد ، إلا أنّه هناك جملة من العقبات أهمها تعديل الاستور التركي ليتماثىى مع المعايير الأوربية في الايموقراطية ، وحقوق الإنسان ،

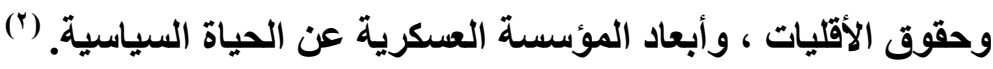
من كل ماتقدم نجدّ أن المعاهدة الدولية أصبح لها تأثير على القاعدة الوطنية الاستورية بطريقة مباشرة عن طريق نصوصها أو بشكل غير مباشر عن طريق مـا تخلقه المعاهدة الدولية من مؤسسات دولية أو أثخاص قانونية دولية كما هو الحال في عندي المنظمات الدولية وهي بدورها أصبحت تؤثر في تعديل القاعدة الاستورية ـ

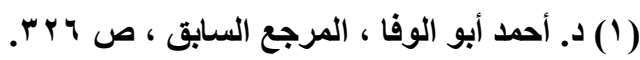

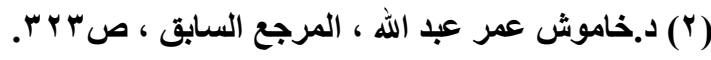

مجلة البحوث القانونيت والإقتصاديت ـ 


\section{الخاتمــــة}

من خلال دراستنا لموضوع دور المعاهدات الدولية في تعديل الدستور ، وجدنا أنّ المنظمات الدولية والإقليمية تفرض معايير قانونية أو سياسية معينة ، قد تكون تلك القيم بخلاف إرادة الشعب ، وفيمـا يتعلق بالمعاهدات الدولية التي تكون متناقضة مع نصوص الاستور والتي تؤدي إلى تعديل الاستور ، وإنّ هذا التعديل قد لايتناسب مـع مبدأ سيادة الشعب ، فإنتا قد استتتجنا من بحثنا النتائج والتوصيات الآتية :-

أولاً :- النتائج : 1. المعاهدات الدوليـة هي اتفاقيات مكتوبـة بين أشخاص القـانون الدولي العام وللمعاهدات مسميات كثيرة مثثل الاتفاقية والميثاق والعهد و النظام والاتفـق والأبروتوكول والبيان والإعلان ، وهناك معاهدات ثنائية وجناعية ومعاهدات شار عة ومعاهدات عقدية . Y. بختلف موقـع الاتفاقيـات الدوليـة في التشريعات العربيـة والأجنبيـة ، بعض الدول تنص دسـاتيرها على أن الاتفاقيـات الدولية تكون درجتها هي درجـة القوانين الوطنية التي يصدرها البرلمـان ، ومن هذه الدول مصر ، لبنـان ، سـوريا ، الأردن ، في حين تـذهب بعض الـدول إلسى أنّ درجـة المعاهـدات والاتفاقيات الاولية تكون أعلى من القوانين الوطنية ، ومن هذه الدول فرنسا، أمسا هنالـك دول أخرى تنص دســتيرها على أنّ درجـة المعاهـدة والاتفاقيـة الاولية تكون هي والدستور الوطني بلرجة واحدة ومن هذه الدول الولايـات المتحدة الأمريكية ، وهولتدا . 
r. إنّ الأمم المتحدة قد تدخل في بعض الأحيان في مسألة وضع وتعديل الدستور ، وتقدم المساعدة الفنية ، وفي أحيان أخرى لا يقتصر الأمر على الأمور القنية بل تفرض معايير قانونية وسياسية معينة، كما أنّ المنظمات الإقليمية تفرض على الدول التي تريد الأنضمام إليها معايير معينة بما فيها تعديل الدستور . ؛. هناك بعض الاساتير تنص على بعض الموضوعات التي لا يجوز المساس بها، أي تثمتع تلك المواد بالحصانة الدستورية تجاه تعديلها أو قيد زمني مثال ذلك دستور العراق لعام ه . . ب الذي حظر تعديل الاستور إلا بعد ثماني سنوات

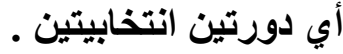

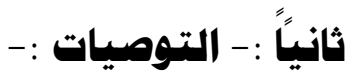

1. احترام مبدأ تلرج التشريعات الدولية والوطنية ؛ لأثّها ليست من درجة واحدة

أو مرتبـة واحدة وإنّــا هذه التشريعات تتدرج مـن حيث قوتها وإلزاميتها ، فالدستور يحتل الدرجة الأولى والأعلى وتأتي القوانين الأساسية في الارجة الثانية .

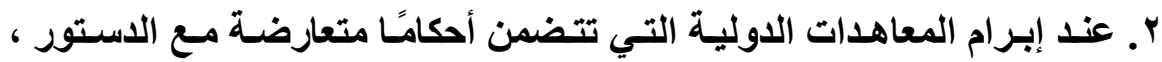
والتي تـؤدي إلى تعديل الدستور ، نوصسي بـأنّ إبرام معاهدة متعارضـة مـع الاستور يجب أن تكون بموافقة الشعب . r. رقابة المحكمة الدستورية العليا على التعديلات الاستورية . 


\section{أولاً :- قائمة الصادر والمراجع}

ا ـ د. إبراهيم أحمد شـلبي ، التنظيم الدولي ( دراسـة في النظريـة العامـة والمنظمـات

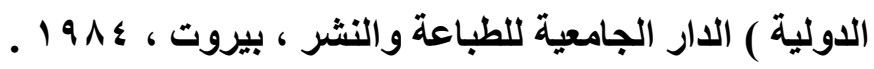

Y. د. إبراهيم عبد العزيز شيحا ، النظم السياسية والقانون الاستوري ، منشأة المعارف

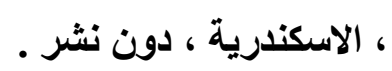

ץ. د.أحمد أبو الوفا ، الوسيط في قانون المنظمات الدولية ، طه ، دار النهضة العربية ، مصر ، . (

؛ ـ د. أحمد فتحي سرور ، الحماية الدستورية للحقوق والحريات ، طץ ، دار الثروق ،

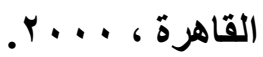

هـ د. إسماعيل غزال ، الدساتير والمؤسسات السياسية ، مؤسسة عز الدين للطباعة

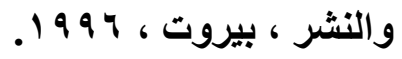

7. د.خاموش عمر عبد الله ، الإطار الدستوري لمساهمة الشعب في تعديل الدستور ،

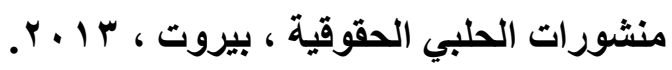

V. د. رجب محمود طاجن ،قيود تعديل الدستور ، دار النهضة العربية ، القاهرة ، طץ

$$
\text { . r... A }
$$

^. د. سعد عصفور ، القانون الاستوري ، دار المعارف ، الاسكندرية ، طا ، ؛ 9 1.

9. د.سليمان الطماوي ، السلطات الثلاث ، دار الفكر العربي ، طج ، القاهرة ، 999 19. 
• 1. د.عيد أحمــ الغفلـول ، فكرة النظـام العـام الدستوري ، دار النهـضة العربيـة ،

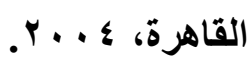

1 ا ـ.دعلي صادق أبو هيف ، القانون الدولي العام ، منشأة المعارف بالاسكندرية ، باون سنة طبع .

r r ـ د. عوض عبد الجليل الترسساوي ، المعاهدات الدولية أمسام القضاء الدستوري (

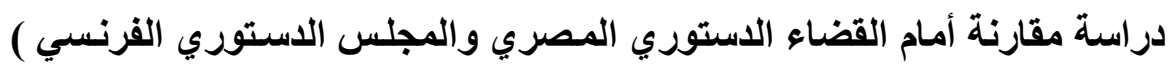

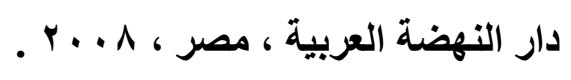

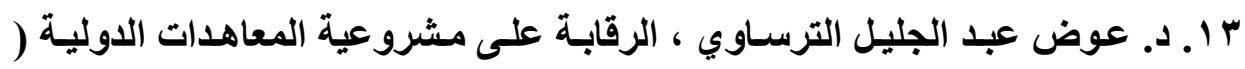

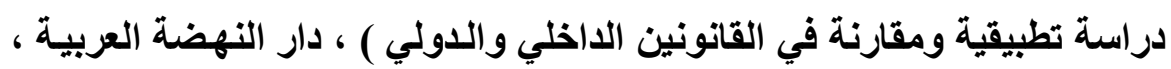

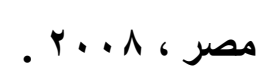

؛ ا ـ د. كمال الغالي ، مبادئ القانون الاستوري والنظم السياسية ، المطبعة الجديدة ،

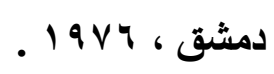

ه ا ـ محمد بـن أبس بكر الرازي ، مختـار الصحاح ، دار الكتـاب العربـي ، بيروت ،

$$
.1911
$$

14 ـ د.محمد فوزي نويجي ، مسؤولية رئيس الاولة في الفقه الإسلامي ، دار الجامعة

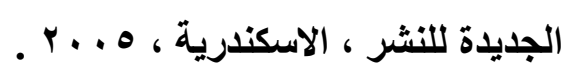

V ا ـ د. محمد فوزي نويجي ، فكرة التدرج للقواعد الاستورية ( دراسة تحليلية نقدية)،

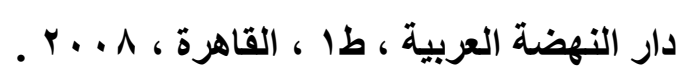


1 ـ دـ منــز الشـاوي ، القـانون الدستوري والمؤسسسات الدستورية ، طץ ، مطبعـة

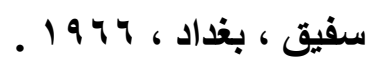

9 ا ـ د. منذر الشاوي ، فلسفة الدولة ، دار ورد الأردنية للنشر والتوزيع ، طا ، عمان . r. Ir 。

• ץ. د. نزيه رعد ، القانون الاستوري العام ، المؤسسة الحديثة للكتاب ، طץ ، بيروت . r...

21. David m . walker claranotion paris , 1980

22. GAMBLE, Reservation to Maltilateral Treaties, Amacroscopic view of state practice, 74 Ajil , 1980

23. M-F. Rigaux, Latheorie des limites materielles a lexeice de la function constituante, paris, Bruxelles, 1985.

24.O.Duhamel et Y. meny, Dictoonnaier constitionnel, puf, paris1992.

25. See R AFalk, on The Quasi _ Legislative Competence of The General dssembly , 66 ATL , 1966. 


$$
\text { ثانيًا : - الدساتير : :- }
$$

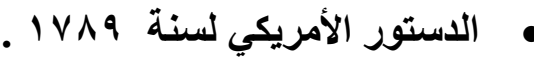

• الاستور اللبناني لسنة 9 ـ 9 ـ

• الاستور الأردني لسنة ro 19 .

• الدستور المصري لسنة I9VI ـ

• الاستور الفرنسي لسنة 1901 ـ

• الاستور الكمبودي لسنة 9 ا ـ ـ

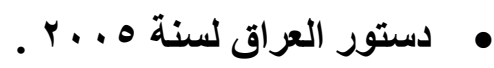

• الاستور البلجيكي لسنة ب99 19 .

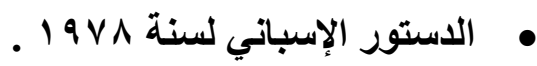

• الدستور الكويتي لسنة بو 199 .

• الاستور الموريتاني لسنة الو 197 ـ

• الاستور البرازيلي لسنة ع ب9 ـ ـ

• الاستور الإيطالي لسنة V \ 19 ـ . 